theory of ions and electrolytic dissociation, but we are bound to admit that this interesting development as it relates to organic chemistry is dismissed somewhat summarily. However, we notice that the corresponding work by the same anthor on inorganic chemistry is referred to as containing a full explanation of the subject. The term "balide" as applied to an iodide, bromide, or chloride will be new to many readers. We like the plan of the book ; it is written in excellent sequence as regards theory and the structure of compounds and should prove to be an excellent companion to the student attending his first course of organic chemistry.

$A$ Short Manual of Analytical Chemistry. By JoHм Nuter, Ph.D., F.I.O., F.C.S. Ninth edition, illustrated. London: Baillière, Tindall, and Cox. 1903. Pp. 235. Price 6s. -Although this work is written within the limits of a special course of instruction, yet we think it will be useful to the general student of analytical chemistry. The author has had considerab!e laboratory experience and the sections bear evidence of his familiarity with the details of both qualitative and quantitative analysis. Special attention is given to the requirements of pharmaceutical students. Necessarily brief as are some of the details in regard to the analysis of foods, drugs, and pathological products, yet they serve to prepare the student for a more exhaustive account of the subject. The author has certainly succeeded in compressing a good deal of material essential to the general student of chemistry in comparatively small compass. To the class of student described the work should prove of undoubted assistance.

Mr. Woodhouse's Correspondence. By G. R. and E. S. London: Methuen and Co. 1903. Pp. 277. Price 6s.This book is indeed "infinite riches in a little room," it is a picture of types exquisitely finished and mostly disagreeable. Mr. Algernon Wentworth-Woodhouse is a widower, eminently selfish, rich, and scrupulously polite. Elaine Thompson, his god-daughter, to whom Mr. Woodhouse with unkind truth writes, "If my memory does not deceive me you were christened Ellen," is also charmingly selfish and has written a work called the Woof-Warp. Hlaine's end, however, is sad, for she finishes her career, in the book at least, by accepting a post under a food depôt to write attractive advertisements. From our own medical point of view, however, the most attractive character is Lady Louisa Fitzwigan who in company with her medical advisers is a perfectly delightful character. Dr. Riley, the honest practitioner, and Dr. Chubb, thewell, we will call him the fashionable one, are contrasted types and by no means overdrawn. Here is Dr. Chubb's mulfin diet which, as Lady Lousia says, was "invented by him and is, I hear, making his fame. The patient takes a hot buttered muffin every two hours and sips a tumbler of tepid water 60 minutes after eating it. The results for delicate dugestions are incredible." G. R. and E. S. are to be congratulated upon a most finished piece of work, the reading of which will give anybody half-an-hour's unalloyed enjoyment.

\section{JOURNALS AND MAGAZINES.}

The Practitioner. - The November number of this journal deals largely with subjects of gynæcological interest. Mr. Alban H. G. Doran contributes an article on the present position of our knowledge with regard to the treatment of uterine fibroids which is more remarkable for its comprehensive survey of rival recommendations than for any decisive conclusions as to the course to be adopted in dealing with fibromyomata in their very various degrees of harmfulness. $\mathrm{Mr}$. Doran does, however, speak strongly of the necessity for keeping even quite innocuous fibroids under observation and here all will agree with him, whether they are keen advocates for early operation in most cases or not. Dr. Thomas J. Eorder writes on the treatment of nephritis and devotes his attention particularly to the views and researches of Professor van Noorden. Some time-honoured plans of dieting the subjects of nephritis certainly seem to be overthrown by the most recent pathological and physiolcgical investigations bearing on the matter. Substantial clinical support of the newer recommendations is still, however, lacking and will, we hope, be earnestly sought

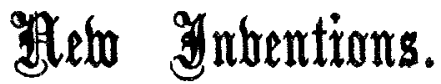

\section{A MODIFIED LARYNGOSCOPIC MIRROR.}

For those who suffer from myopia, and more especially from hypermetropia, I venture to hope that the following addition to the forehead mirror of the laryrgoscofe may be fcund useful. This addition consists of a circular metal plate carrying various plus and minus lenses riveted to the metal back of the forehead mirror in such a manner that any required lens can be brought into position behind the aperture (vide diagram). This apparatus will be found much

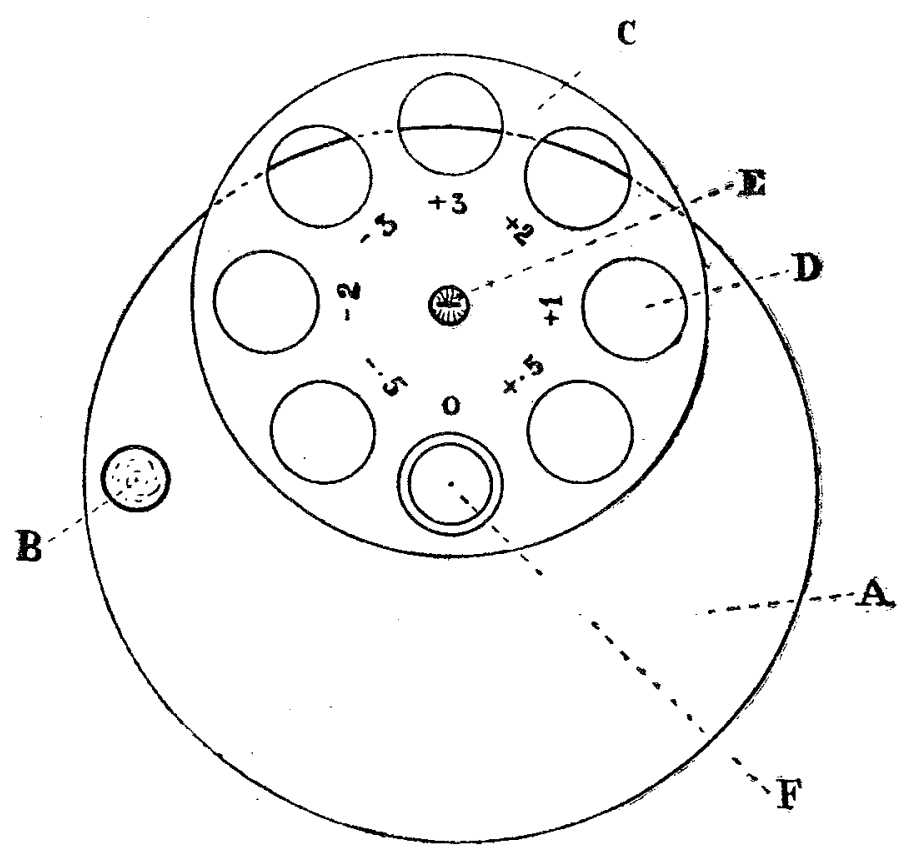

A, The back of an ordinary laryngoscopic forehead mirror. B Knob for fixing by ball and-socket joint to the forebead band. c, Metal plate carrying various lenses fixed to the back of the forehead mirror. $D$, Lens which can be rotated so that it comes behind the aperture in the centre of the forehead mirror. E, Rivet fixing metal plate to the metal back of the forehead mirror. F, Inner circle represents the aperture in the for ehead mirror; the outer circle represents the aperture in the metal plate, in this case carrying no lens.

more satisfactory than the method of wearing eye-glasses and having the mirror in the centre of the forehead. The instrument which I have was specially made to my own specifications by Messrs. Archibald Young and Sons, Horrestroad, Edinburgh.

Ian Struthers Stewart, M. B., Ch.B. Edin. Nordrach-on-Dee, Banchory, N.B.

Society of Members of The Royal College of SURGEONS OF ENGLAND. - The annual general meeting and dinner of this society were held on Nov. 10th. Mr. Joseph Smith was reelected President, Dr. G. Danford Thomas, Mr. T. Martin, and Dr. Herbert Snow were elected Vice Presidents, Mr. J. Brindley James was elected honorary treasurer, and Dr. W. G. Dickinson honorary secretary. At the subsequent dinner the toast of "The Society" was proposed by Mr. W. Gibson Bott and responded to by the President. Mr. H. Nelson Hardy proposed "Tre Officers of the Society" and urged the importance of bringing pressure to bear on Members of Parliament and others in order to promote the just claims of the Members of the College. Dr. Danford Thomas, Mr. Martin, and the secretary replied. During the evening Mr. Sidney Gandy gave an entertainment and the President and others contributed masic. 